\title{
Evidence-Based Practice and Job Satisfaction of Nurses in Long-Term Care
}

\author{
Hyunwook Kang \\ Department of Nursing, Kangwon National University, Chuncheon, South Korea \\ Email: hyunwkang@gmail.com
}

How to cite this paper: Kang, H. (2016) Evidence-Based Practice and Job Satisfaction of Nurses in Long-Term Care. Open Journal of Nursing, 6, 977-986.

http://dx.doi.org/10.4236/ojn.2016.612094

Received: November 2, 2016

Accepted: November 28, 2016

Published: December 1, 2016

Copyright $\odot 2016$ by author and Scientific Research Publishing Inc. This work is licensed under the Creative Commons Attribution International License (CC BY 4.0).

http://creativecommons.org/licenses/by/4.0/

(c) (i) Open Access

\begin{abstract}
Purpose: The purpose of this study was to identify the relationship between evidence-based practice (EBP) and job satisfaction among nurses working in long-term care facilities. Methods: The study used a descriptive cross-sectional design. A total of 146 nurses working in 6 long-term care facilities in South Korea self-reported their perception of EBP implementation, barriers to research utilization, and job satisfaction. Results: The level of job satisfaction was higher in nurses who were single, older, more experienced, and had a higher income. Lower perceived barriers to research utilization were associated with greater job satisfaction. However, there was no significant relationship between a level of EBP implementation and job satisfaction. Factors influencing job satisfaction included lower barriers to the organization and communication domains of research utilization, being unmarried and older. Conclusion: Decreasing barriers to research utilization may improve the job satisfaction of nurses working in long-term care facilities.
\end{abstract}

\section{Keywords}

Evidence-Based Practice, Job Satisfaction, Long-Term Care, Nurse

\section{Introduction}

The rapid increase in the aging population has led to concern about the quality of nursing care in long-term care (LTC) facilities in South Korea. Nurses are key healthcare professionals responsible for providing optimal care to older adults in LTC facilities. However, numerous studies have suggested that nurses working in LTC facilities had low job satisfaction, resulting in strong intentions to leave and high turnover rates [1].

Various factors reportedly influenced the job satisfaction of nurses working in LTC 
facilities: demographic factors included age and education level [2], and work-related factors included job conflict, rewards, care quality, staffing, and promotional opportunities [3] [4]. Also, nurses working in LTC facilities have consistently reported that a lack of professional knowledge on gerontological nursing could lower the quality of care [5] [6]. In addition, nurses included in a qualitative study reported that they perceived higher job satisfaction when the health status of elderly patients improved due to the quality of care that they provided [5].

EBP is commonly defined as the integration of the best research findings, clinical expertise, and patients' preferences within a context of caring [7]. The utilization of research evidence is essential for implementing and sustaining EBP [8]. EBP implementation can ensure the quality of care because it uses guidelines or protocols based on clinical expertise and a considerable number of research findings that have been repeatedly found to be effective. EBP led to better health outcomes than traditional care [9], which has prompted considerable efforts to improve the quality of nursing care using EBP (mainly in hospitals), whereas the nurses' use of EBP in LTC facilities has received little attention. This discrepancy may be because EBP requires substantial effort and time from nursing staff, which are scarce resources in most LTC facilities. Indeed, many studies have reported that lack of resources, organizational culture supporting EBP, and EBP knowledge discouraged clinicians or nurses from using EBP [10] [11]. Older adults are less likely to be able to take care for themselves due to the presence of complex health problems such as dementia and other chronic diseases, and physical impairment, which exacerbates the problem of limited resources [12]. However, there are advantages of applying EBP in LTC, such as nurses being able to practice more effectively, and this can ensure the best use of the available resources [12].

The conceptual framework that guided the present study was the Nursing Organization and Outcomes Model [13]. This model posits that five dimensions of the nursing practice environment are strong predictors of job satisfaction of nurses: participation in facility organization, foundations for quality care, adequate resources, a supportive manager, and collaborative relationships between registered nurses (RNs) and physicians. This model was supported by the results obtained in studies performed in acutecare and LTC facilities [3] [14] [15]. The foundations for quality care can be achieved by the implementation of EBP.

The purpose of this study was to identify the relationships among EBP implementation, barriers to research utilization, and job satisfaction of nurses working in LTC facilities. Specific aims were to identify 1) the level of job satisfaction, the level of EBP implementation, and perceived barriers to research utilization, and 2) the factors influencing job satisfaction among nurses working in LTC facilities.

\section{Methods}

\subsection{Study Design}

This study used a cross-sectional descriptive design. 


\subsection{Sample and Setting}

A total of 146 nurses participated in this study. The inclusion criteria were RNs who 1) had worked more than 2 month in the present facility and 2) were aged 20 years or older. Data were collected from six LTC facilities in D city in South Korea. The number of bed sizes in the participating facilities ranged from $99-269$.

\subsection{Measurement}

Job Satisfaction. The job satisfaction of nurses was measured using the Index of Work Satisfaction that was originally developed by Slavitt and colleagues [16] and translated into Korean by Lee [17]. This Korean version of the index has been used in many Korean nursing studies [18] [19]. This instrument uses a 5-point Likert scale (from 5 = "strongly agree" to 1 "strongly disagree") to score 40 items in 6 domains (autonomy, interaction, professional status, task requirement, payment, and organizational policies). The total score ranges from 40 to 200, with a higher score indicating greater job satisfaction. Cronbach's alpha values for the instrument in previous studies were 0.91 [17] and 0.89 [18].

Evidence-Based Practice Implementation. Participants self-reported the level of EBP implementation in their present facility on a 4 -point Likert scale $(1=$ none, $2=\mathrm{a}$ little, $3=$ moderate, and $4=$ a lot).

Barriers to Research Utilization. The BARRIERS scale [20] was used to measure the extent of barriers to research utilization by nurses. This instrument consists of 28 items in 4 domains: adopter, organization, research, and communication. Another item was subsequently added to measure the extent to which English becomes a barrier to research utilization when studies using this measurement were conducted in non-English-speaking countries. Each item is rated from 1 ("to no extent") to 4 ("to a great extent"), with 0 for "no opinion". Numerous research studies have found the BARRIERS scale to have sound psychometric properties [6]. A Korean version of the BARRIERS scale, developed and tested by Oh [21], was administered to the present participants. The internal consistency reliability in the present study ranged from 0.74 to 0.87 by domains.

Demographic Characteristics. The analyzed demographic characteristics included age, sex, marital status, education level, monthly wages, years of clinical experience, and position in the present facility.

\subsection{Ethical Considerations}

Before the study commenced, the author explained the purpose and procedure of the study to the participants and assured that their participation would be voluntary, and that they could withdraw from the study without any harm or disadvantage. The information for participants also included that personal identifiers would be disclosed only to members of the research team, they would be stored in a locked cabinet and the author's personal computer protected by passwords, and code numbers would be generated and used in data analyses to ensure anonymity. 


\subsection{Data Collection}

After obtaining approval from the Institutional Review Board of K university hospital, the author compiled a list of LTC facilities in K province of Korea, and made phone calls to the directors of nursing (DONs) of those facilities to initiate recruitment. The author visited DONs who agreed to be visited and wanted to hear about this study. Finally, DONs of 6 facilities agreed to participate in this study after the author explained its purpose and procedures. Nurses who agreed to participate signed and dated consent documents before they completed the study questionnaires. The author posted questionnaires in packages that included stamps for returning the completed questionnaires by mail for nurses who were off duty or on night duty.

\subsection{Data Analysis}

The collected data were entered into the Excel program and analyzed by SPSS version16. Frequency, percentage, mean (M), and standard deviation (SD) values were generated to provide descriptive data of the demographic characteristics of the participants and other variables. ANOVA, t-tests, and Pearson's correlation coefficient analyses were conducted to identify correlations among demographic characteristics, levels of EBP implementation, barriers to research utilization, and job satisfaction. In the BARRIERS scale, responses of "no opinion" were excluded from the statistical analysis. Stepwise regression was used to identify factors that significantly influenced job satisfaction.

\section{Results}

Data collected from 146 nurses were analyzed. Table 1 presents demographic characteristics and their relationships with job satisfaction. The overall mean job satisfaction score was $2.94(\mathrm{SD}=0.43)$, while the score within domains was highest for the interaction domain $(\mathrm{M}=3.43, \mathrm{SD}=0.52)$.

The autonomy domain had the second highest score $(\mathrm{M}=3.28, \mathrm{SD}=.54)$, followed by the task requirement $(\mathrm{M}=3.01, \mathrm{SD}=0.43)$, professional status $(\mathrm{M}=2.77, \mathrm{SD}=$ $0.64)$, organizational policies $(\mathrm{M}=2.49, \mathrm{SD}=0.59)$, and payment $(\mathrm{M}=2.14, \mathrm{SD}=0.68)$ domains (Table 2).

Regarding EBP implementation, only 110 nurses responded the questionnaire.46.0\% $(n=64)$ of the nurses reported that they implemented EBP, while $33.1 \%(n=46)$ of them were not aware whether or not they were implementing EBP in the facility where they worked.

Regarding barriers to research utilization, the participants reported that the communication domain was the greatest barrier, followed by the organization, research, and adopter subscales (in that order) (see Table 2). A rank order was generated based on the percentage of participants responding that there were "moderate" or "great" barriers to research utilization [6]. According to this rank order, "Research reports/articles being written in English constitutes a barrier" was the greatest barrier to research utilization, followed by "The nurse feels results are not generalizable to her/his own setting" 
Table 1. Demographic characteristics and their relationships with job satisfaction $(\mathrm{N}=146)$.

\begin{tabular}{|c|c|c|c|c|}
\hline \multirow{2}{*}{ Variable } & \multirow[t]{2}{*}{ Category } & \multirow[t]{2}{*}{$\mathrm{M}(\mathrm{SD})$ or $\mathrm{n}(\%)$} & \multicolumn{2}{|c|}{ Relationship with job satisfaction } \\
\hline & & & $\mathrm{M}(\mathrm{SD})$ & $\mathrm{t} / \mathrm{F} / \mathrm{r}(\mathrm{p})$ \\
\hline Age (years) & - & $33.32(7.83)$ & - & $0.436(<0.001)$ \\
\hline Sex & Female & $146(100)$ & - & - \\
\hline \multirow[t]{2}{*}{ Education } & 3 -year college graduate & $119(81.5)$ & $107.14(15.39)$ & $2.856(0.061)$ \\
\hline & Bachelor or over & $27(18.5)$ & $115.19(18.53)$ & - \\
\hline \multirow[t]{2}{*}{ Marital status } & Single or separated & $81(55.5)$ & $113.10(16.69)$ & $5.862(0.001)$ \\
\hline & Married & $65(44.5)$ & $102.62(13.12)$ & - \\
\hline $\begin{array}{c}\text { Clinical experience } \\
\text { (years) }\end{array}$ & - & $8.66(5.09)$ & - & $0.180(0.044)$ \\
\hline \multirow[t]{3}{*}{ Position } & Staff nurse & $111(77.1)$ & $106.56(15.85)$ & $3.999(0.009)$ \\
\hline & Charge nurse & $14(9.7)$ & $110.64(12.27)$ & - \\
\hline & Unit manager & $19(13.2)$ & $117.05(16.23)$ & - \\
\hline \multirow[t]{2}{*}{$\begin{array}{l}\text { Monthly wages } \\
\text { (1000 won) }\end{array}$} & $100-\leq 200$ & $123(84.8)$ & $106.74(1.33)$ & $-3.621(<0.001)$ \\
\hline & $>200$ & $22(15.2)$ & $119.64(18.67)$ & - \\
\hline
\end{tabular}

Table 2. Relationships among EBP implementation, barriers to research utilization and job satisfaction $(\mathrm{N}=146)$.

\begin{tabular}{|c|c|c|c|c|}
\hline Variable & Category & $\mathrm{M}(\mathrm{SD})$ or $\mathrm{n}(\%)$ & & \\
\hline \multirow[t]{7}{*}{ Job satisfaction } & Autonomy & $3.28(0.54)$ & & \\
\hline & Interaction & $3.43(0.52)$ & & \\
\hline & Professionalism & $2.77(0.64)$ & & \\
\hline & Organization & $2.49(0.59)$ & & \\
\hline & Task & $3.01(0.43)$ & & \\
\hline & Pay & $2.14(0.68)$ & & \\
\hline & Total & $2.94(0.43)$ & & \\
\hline \multicolumn{3}{|c|}{ Relationship with job satisfaction } & $\mathrm{M}(\mathrm{SD})$ & $\mathrm{t} / \mathrm{F} / \mathrm{r}(\mathrm{p})$ \\
\hline \multirow[t]{4}{*}{$\begin{array}{c}\text { Level of EBP } \\
\text { implementation }^{\mathrm{a}}\end{array}$} & Well & $16(11.5)$ & $115.06(19.63)$ & $0.708(0.495)$ \\
\hline & A little & $48(34.5)$ & $109.90(15.45)$ & \\
\hline & None & $29(20.9)$ & $109.69(14.87)$ & \\
\hline & Unknown & $46(33.1)$ & $105.41(16.56)$ & \\
\hline \multirow[t]{4}{*}{$\begin{array}{l}\text { Barriers to } \\
\text { research utilization }\end{array}$} & Adopter & $2.11(0.98)$ & - & $-0.341(<0.001)$ \\
\hline & Organization & $2.49(0.97)$ & - & $-0.482(<0.001)$ \\
\hline & Research & $2.36(0.91)$ & - & $-0.117(0.169)$ \\
\hline & Communication & $2.51(0.94)$ & - & $-0.311(<0.001)$ \\
\hline
\end{tabular}

a. $\mathrm{n}=110$ (no response excluded). 
(data not shown). Correlation analyses revealed that there were significant relationships between job satisfaction and age $(\mathrm{r}=0.436, p<0.001)$, marital status $(\mathrm{t}=5.862, p=$ $0.001)$, clinical experience $(\mathrm{r}=0.180, p=0.044)$, position $(\mathrm{F}=3.999, p=0.009)$, monthly wages $(\mathrm{t}=-3.621, p<0.001)$. Also, three domains of the BARRIERS scale had significant relationships with job satisfaction: adopter $(\mathrm{r}=-0.341, p<0.001)$, organization $(\mathrm{r}=-0.482, p<0.001)$, and communication ( $\mathrm{r}=-0.311, p<0.001)$ domains. However, the level of EBP implementation and the score for the research domain of the BARRIERS scale were not significantly related to job satisfaction (Table 2).

The stepwise regression model showed that age $(\beta=0.220, p=0.027)$, marital status $(\beta=-0.207, p=0.007)$, and the organization $(\beta=-0.384, p<0.001)$ and communication $(\beta=-0.175, p=0.034)$ domains of the BARRIERS scale were significant predictors of job satisfaction. This model explained $39.5 \%$ of the total variance $(\mathrm{F}=19.734, p<$ 0.001) (Table 3).

\section{Discussion}

This study has identified the relationships between EBP implementation, barriers to research utilization, and job satisfaction among nurses working in LTC facilities. As Table 2 indicates, the overall level of job satisfaction of the participants was 2.94 (SD = 0.43). This score is slightly lower than those found in previous studies that used the similar instrument. Among studies that investigated the job satisfaction of nurses working in LTC facilities, the score for job satisfaction was $3.11(\mathrm{SD}=0.39)$ in the study of Park et al. [19] and 3.25 ( $\mathrm{SD}=0.33$ ) in the study of Song [22]. This discrepancy might be due to the present study being conducted in rural areas, whereas the participants in other studies worked in urban areas [22] or in geographically diverse settings [19]. LTC facilities in rural areas are likely to have lower staffing and financial resources, which might result in high turnover rates or low wages and hence lower scores for job satisfaction.

Nurses perceived the greatest job satisfaction for the interaction domain, followed by the autonomy and task requirement domains, whereas they reported the lowest job satisfaction for the payment domain. These findings are consistent with previous studies finding that the job satisfaction of nurses working in LTC was highest for the interaction

Table 3. Factors influencing job satisfaction $(\mathrm{N}=146)$.

\begin{tabular}{cccccc}
\hline \multirow{2}{*}{ Variable } & \multicolumn{5}{c}{ Variables } \\
\cline { 2 - 6 } & $\mathrm{B}$ & $\mathrm{SE}$ & $\beta$ & $\mathrm{t}$ & $p$ \\
\hline Age & -1.136 & 0.247 & -0.384 & -4.605 & $<0.001$ \\
Organization domain of BARRIERS & 0.472 & 0.211 & 0.220 & 2.238 & 0.027 \\
Marital status $^{\mathrm{a}}$ & -6.990 & 3.286 & -0.207 & -2.127 & 0.007 \\
Communication domain of BARRIERS $^{\text {Adjusted } \mathrm{R}^{2}}$ & -0.747 & 0.349 & -0.175 & -2.142 & 0.034 \\
& & & & \\
\hline
\end{tabular}

a. $0=$ single or separated, $1=$ married. 
domain but the lowest for the payment domain [19] [22]. Hospital nurses also reported that they were satisfied the most with their relationships with coworkers and satisfied the least with compensations and benefits, although their overall level of job satisfaction was higher than that of LTC nurses [23]. These results suggest the importance of interactions among colleagues and wage levels to the job satisfaction of nurses.

There was no significant association between the levels of EBP implementation and job satisfaction. However, barriers to research utilization, especially on the organization and communication domains of the BARRIERS were significantly but negatively related to job satisfaction.

The organization subscale refers to "the extent to which nurses perceive barriers and limitations in work settings" [20]. These findings are consistent with those of a previous study [24] that investigated relationships among the organizational culture for EBP, EBP beliefs, EBP implementation, and job satisfaction in a community hospital. Those authors also found no significant relationship between EBP implementation and job satisfaction. Other studies have repeatedly found that the organizational culture or work environment, such as having supportive manager or adequate resources, was strongly and positively related to job satisfaction [3] [24]. Therefore, these findings suggest that the job satisfaction of nurses is highly dependent on organizational support that may empower them in delivering high-quality care.

A possible explanation for the finding of no correlation between EBP implementation and job satisfaction is that implementing EBP might not directly influence job satisfaction; instead, the health outcome or quality of care of patients resulting from EBP adoption seems to be associated with job satisfaction. This result did not support the hypothesis of the Nursing Organization and Outcomes Model [13] that foundations of quality care was one of predictors of job satisfaction of nurses. However, further investigations are required into the relationship between these two variables, because few studies have examined how EBP implementation influences job satisfaction and most studies have used health outcomes of patients as dependent variables when EBP implementation was used as an independent variable.

The communication subscale of the BARRIERS scale, which refers to "the extent to which the nurses perceive the presentation and accessibility of the research as barriers to research utilization" [20], was significantly negatively related to job satisfaction. This suggests that nurses perceive a higher level of job satisfaction when they have a greater understanding of or access to work-related research or information. Indeed, previous studies have shown that nurses working in LTC facilities perceived a great need for in-depth and more-recent gerontological nursing knowledge. Since LTC facilities are less likely to have in-house physicians, many nurses working in LTC facilities frequently face critical situations in which they need to make clinical decisions in emergencies or to provide immediate help without physicians based on their own advanced medical or nursing knowledge as well as clinical experiences [5] [25]. However, it seems that nurses working in LTC facilities lack opportunities to receive education about recent and advanced knowledge on older adults. The content analysis involving short answers 
on the additional barriers to research utilization revealed that most findings from nursing research were not applicable to older patients, and nurses needed continuous education about gerontological nursing. The nurses also emphasized the importance of the working environment to facilitating new ideas or knowledge regarding elderly care in the use of research findings [6]. Thus, nurses working in LTC facilities need to be provided with tailored education strategies including readily accessible and understandable information on a regular basis. Hines et al. [26] suggested that interactive and activity-based learning interventions seemed to be effective at improving the research knowledge of nurses and their ability to critically review the literature.

Among demographic characteristics, nurses who were older, unmarried, and had more clinical experience and higher income experienced greater job satisfaction. This is consistent with previous studies [27] suggesting that nurses with greater experience and higher wages would be more satisfied with their jobs.

This study was subject to two main limitations. First, data were collected in only one province of Korea, and combined with the use of a convenience sampling method this may limit the generalizability of the study findings. Second, although the participants put their completed questionnaires in opaque envelopes when returning them to the research team, the moderate response rate $(67.3 \%)$ implies that the questions might have been uncomfortable for the nurses to answer, and so some of the responses might have biased in the direction of social desirability.

\section{Conclusion}

This study found that nurses working in LTC facilities perceived the greatest job satisfaction from their interactions with coworkers and managers, and the lowest job satisfaction from their wages. Overall, the level of job satisfaction of the participants in this study was lower than that found in previous studies. Perceived barriers to organizational support and the accessibility and understandability of research reports were factors lowering the job satisfaction of the included nurses. However, there was no significant relationship between the level of perceived EBP implementation and job satisfaction. Future studies need to investigate whether the long-term implementation of particular nursing interventions using EBP would improve the job satisfaction of nurses working in LTC facilities.

\section{Acknowledgements}

This research was supported by Basic Science Research program through the National Research Foundation of Korea (NRF) funded by the Ministry of Science, ICT \& Future Planning (Grant no. 2012R1A1A1015667).

\section{References}

[1] Grillo, G., Kash, B.A., Naufal, G.S., Dagher, R.K. and Johnson, C.E. (2010) Individual Factors Associated with Intentions to Leave among Directors of Nursing in Nursing Homes. Health Care Management Review, 35, 246-255.

https://doi.org/10.1097/HMR.0b013e3181dc826d 
[2] Karsh, B., Booske, B.C. and Sainfort, F. (2005) Job and Organizational Determinants of Nursing Home Employee Commitment, Job Satisfaction and Intent to Turnover. Ergonomics, 48, 1260-1281. https://doi.org/10.1080/00140130500197195

[3] Choi, J., Flynn, L. and Aiken, L.H. (2011) Nursing Practice Environment and Registered Nurses' Job Satisfaction in Nursing Homes. The Gerontologist, 52, 484-492.

https://doi.org/10.1093/geront/gnr101

[4] Tyler, D.A., et al. (2006) An Exploration of Job Design in Long-Term Care Facilities and Its Effect on Nursing Employee Satisfaction. Health Care Management Review, 31, 137-144. https://doi.org/10.1097/00004010-200604000-00007

[5] Chung, S.E. and Lee, S.H. (2009) Nurses' Experience of Practice in Nursing Homes. Journal of Korean Academy of Nursing Administration, 15, 116-127.

[6] Kang, H. (2015) Geriatric Hospital Nurses' Perceived Barriers to Research Utilization and Empowerment. Asian Nursing Research, 9, 65-72. https://doi.org/10.1016/j.anr.2014.11.005

[7] Melnyk, B.M., Fineout-Overholt, E., Stetler, C. and Allan, J. (2005) Outcomes and Implementation Strategies from the First US Evidence-Based Practice Leadership Summit. Worldviews on Evidence-Based Nursing, 2, 113-121. https://doi.org/10.1111/j.1741-6787.2005.00022.x

[8] Stetler, C.B. (2001) Updating the Stetler Model of Research Utilization to Facilitate Evidence-Based Practice. Nursing Outlook, 49, 272-279.

https://doi.org/10.1067/mno.2001.120517

[9] Grimshaw, J., et al. (2006) Toward Evidence-Based Quality Improvement. Journal of General Internal Medicine, 21, S14-S20.

[10] Fineout-Overholt, E., Melnyk, B.M. and Schultz, A. (2005) Transforming Health Care from the Inside Out: Advancing Evidence-Based Practice in the 21st Century. Journal of Professional Nursing, 21, 335-344. https://doi.org/10.1016/j.profnurs.2005.10.005

[11] Hutchinson, A.M. and Johnston, L. (2006) Beyond the BARRIERS Scale: Commonly Reported Barriers to Research Use. Journal of Nursing Administration, 36, 189-199. https://doi.org/10.1097/00005110-200604000-00008

[12] Specht, J.K. (2013) Evidence Based Practice in Long Term Care Settings. Journal of Korean Academy of Nursing, 43, 145-153. https://doi.org/10.4040/jkan.2013.43.2.145

[13] Aiken, L.H., Clarke, S.P. and Sloane, D.M. (2002) Hospital Staffing, Organization, and Quality of Care: Cross-National Findings. Nursing Outlook, 50, 187-194. https://doi.org/10.1067/mno.2002.126696

[14] McHugh, M.D., Kutney-Lee, A., Cimiotti, J.P., Sloane, D.M. and Aiken, L.H. (2011) Nurses' Widespread Job Dissatisfaction, Burnout, and Frustration with Health Benefits Signal Problems for Patient Care. Health Affairs, 30, 202-210. https://doi.org/10.1377/hlthaff.2010.0100

[15] Patrician, P.A., Shang, J. and Lake, E.T. (2010) Organizational Determinants of Work Outcomes and Quality Care Ratings among Army Medical Department Registered Nurses. Research in Nursing \& Health, 33, 99-110.

[16] Slavitt, D.B., Stamps, P.L., Piedmont, E.B. and Hasse, A.M.B. (1978) Nurses' Satisfaction with Their Work Situation. Nursing Research, 27, 114-120. https://doi.org/10.1097/00006199-197803000-00018

[17] Lee, S.S. (1996) A Comparison Study on the Level of Job Satisfaction of Operating Room and Recovery Room Nurses. Korea Association of Operating Room Nurses, 4, 25-48.

[18] Son, S.S. and Yang, S.J. (2014) Job Stress and Job Satisfaction among Nurses in Gastrointestinal Endoscopy Units. Journal of Korean Clinical Nursing Research, 20, 189-199. 
[19] Park, Y.O., Lee, K.J., Cho, E. and Park, H.J. (2009) Factors Affecting Turnover Intention of Nurses in Long-Term Care Facilities for Elderly People. Journal of Korean Gerontological Nursing, 11, 81-89.

[20] Funk, S.G., Champagne, M.T., Wiese, R.A. and Tornquist, E.M. (1991) BARRIERS: The Barriers to Research Utilization Scale. Applied Nursing Research, 4, 39-45. https://doi.org/10.1016/S0897-1897(05)80052-7

[21] Oh, E.G. (2008) Research Activities and Perceptions of Barriers to Research Utilization among Critical Care Nurses in Korea. Intensive and Critical Care Nursing, 24, 314-322. https://doi.org/10.1016/j.iccn.2007.12.001

[22] Song, M.-S. (2013) The Relationships between the Empowerment Nursing Performance, Job Satisfaction and Turnover Intention of Long-Term Care Hospital Nurses. Journal of the Korea Academia-Industrial Cooperation Society, 14, 2304-2314. https://doi.org/10.5762/KAIS.2013.14.5.2304

[23] Sung, K. (2012) Comparison between Nursing Home Nurses and Hospital Nurses for Emotional Labor and Job Satisfaction. Journal of Korean Gerontological Nursing, 14, 40-49.

[24] Melnyk, B.M., Fineout-Overholt, E., Giggleman, M. and Cruz, R. (2010) Correlates among Cognitive Beliefs, EBP Implementation, Organizational Culture, Cohesion and Job Satisfaction in Evidence-Based Practice Mentors from a Community Hospital System. Nursing Outlook, 58, 301-308. https://doi.org/10.1016/j.outlook.2010.06.002

[25] Wells, Y., Foreman, P., Gething, L. and Petralia, W. (2004) Nurses' Attitudes toward Aging and Older Adults. Journal of Gerontological Nursing, 30, 5-13. https://doi.org/10.3928/0098-9134-20040901-04

[26] Hines, S., Ramsbotham, J. and Coyer, F. (2015) The Effectiveness of Interventions for Improving the Research Literacy of Nurses: A Systematic Review. Worldviews of Evidenced Based Nursing, 12, 265-272. https://doi.org/10.1111/wvn.12106

[27] Fung-Kam, L. (1998) Job Satisfaction and Autonomy of Hong Kong Registered Nurses. Journal of Advanced Nursing, 27, 355-363.

https://doi.org/10.1046/j.1365-2648.1998.00527.x

\section{Submit or recommend next manuscript to SCIRP and we will provide best service for you:}

Accepting pre-submission inquiries through Email, Facebook, LinkedIn, Twitter, etc. A wide selection of journals (inclusive of 9 subjects, more than 200 journals)

Providing 24-hour high-quality service

User-friendly online submission system

Fair and swift peer-review system

Efficient typesetting and proofreading procedure

Display of the result of downloads and visits, as well as the number of cited articles

Maximum dissemination of your research work

Submit your manuscript at: http://papersubmission.scirp.org/

Or contact ojn@scirp.org 